\title{
EL CASO DE LA DAMA DE ELCHE: MÁS QUE UNA DIVERGENCIA
}

\author{
POR \\ RICARDO OLMOS y TRINIDAD TORTOSA \\ Centro de Estudios Históricos, C.S.I.C.
}

\section{RESUMEN}

Una reciente recensión de Karen D. Vitelli aparecida en American Journal of Archaeology $(1995,775)$ sobre el libro de John F. Moffitt Art Forgery. The case of the Lady of Elche, es el motivo de nuestro escrito. Se discute aquí el método y contenido de un libro con intención científica y conclusiones inaceptables. La Dama de Elche merece una mejor aproximación desde la luz de la nueva investigación de la arqueología ibérica.

\section{SUMMARY}

A recent review of Karen D. Vitelli appeared in American Journal of Archaeology $(1995,775)$ on John F. Moffitt's Art Forgery. The case of the Lady of Elche, is the reason that make us to write this paper. It is discussed here both metho and content of a book showing a scientific intention but in aceptable conclusions. The Lady of Elche deserves a better approach from the light of the new Iberian archaeological research.

La deconstrucción de mitos y discursos científicos parece una moda arraigada en estas últimas décadas del siglo Xx. Nuevos mitos surgen que sustituyen a aquéllos. En la historia del arte o de la arqueología, el éxito social del falsificador pone de manifiesto la fragilidad de la investigación y la especulación desenfrenada del mercado del arte. Son las falsificaciones reverso inevitable de la medalla del positivismo. Forman parte de la comercialización del pasado. Podrán ser burla y reacción ante lo sagrado y consensuado como verdadero. El falsificador, alter ego del hermeneuta o del artista, tiene también algo de destructor. La infiltración de la obra trucada es cilicio de humildad contra la presunción de la ciencia, inquietud para el coleccionista, motivo de recelo y escepticismo a los ojos del gran público. El desvelamiento

\footnotetext{
"Este trabajo se incluye en el proyecto Iconografía y te rritorio en época ibérica: las cuencas del Vinalopó y del Segura, financiado por la DGICYT, $\mathrm{n}^{\circ}$ PS 93-0006.
}

de una falsificación será objeto de alegría para el profano, que gozará viendo caer ciertos ídolos de barro levantados esforzadamente por la historia ${ }^{1}$.

Los imprecisos límites entre lo verdadero y lo falso - uno de los mensajes de la exposición del British Museum Fake? The Art of Deception (Londres, 1990)- son siempre especial motivo de debate en arqueología. Sobre todo, en la arqueología cómplice del coleccionismo, aquélla que no se acompaña de una precisa certificación contextual en qué arroparse. La inseguridad dilatará las expectativas de nuestro conocimiento. Fue, sin duda, lección provechosa aquel Coloquio de 1992 promovido por la J. Paul Getty Trust (1993) ante el incierto kouros adquirido por esta institución americana. El debate quedó abierto, inconcluso, pero al menos supuso una reacción lógica y fecunda ante el posible engaño de quienes lo adquirieron como auténtica escultura arcaica. Un sutil juego de valores sociales y consenso en ciencia se mueve detrás del coleccionismo ambiguo de lo verdadero y de lo falso ${ }^{2}$.

Este complejo marco podría hoy explicar - pero no justificar - ciertas incursiones aventureras por parte del mismo poder académico. Pues, en medio de la gran polvareda, cabe añadir el engaño -o el autoengaño - de inventar lo falso bajo la retórica aparente de un pensamiento científico. Tal, creemos, es el discurso del libro del profesor John F. Moffitt (Art Forgery: The Case of the Lady of Elche, Florida, 1995), desafortunadamente recensionado por Karen D. Vitelli en las páginas del American Journal of Archaeology (1995, 775). La recensionista desconoce por completo el tema y no ha contrastado las afirmaciones de nuestro autor. Brevemente,

\footnotetext{
1 Un texto más sintético hemos enviado como artículorecensión a American Journal of Archaeology.

${ }^{2}$ Para la retórica científica, cf. Latour, B., Science in Action, Milton Keynes: Open University Press, 1987.
} 
no satisfecho Moffitt con inventar la falsificación de la Dama de Elche, reinventa además la investigación de la arqueología ibérica. Aparte del efímero revuelo en la prensa diaria, no resultan convincentes sus argumentos circulares. In cauda venenum: el libro podrá, al menos, revolverse contra sí mismo y despertar en el ámbito internacional un tema adormecido, actuando, sin pretenderlo, como acicate científico. Por tanto, en este juego de la contestación, no del silencio cómplice o desdeñoso, hemos de plantear la apuesta que lleve a un mejor conocimiento de la escultura ibérica.

Parece intención de John Moffitt ir más allá del desenmascaramiento de una pieza arqueológica excepcional. Pretende, sobre todo, deconstruir lo que construyó antes un siglo de literatura popular y científica, a veces no menos exenta de retórica que la de nuestro autor ${ }^{3}$. El asunto, efectivamente, se presenta intensamente cargado de ideología y de pasión colectiva. Pues hay obras de arte, como la Dama de Elche, sin duda la pieza más emblemática de la arqueología protohistórica española, que van más allá de sí mismas, convirtiéndose en símbolo político, social y estético de una comunidad y de toda una época ${ }^{4}$. La escultura se descubre en 1897 , en el yacimiento ibérico de La Alcudia (Elche, Alicante), y se transforma enseguida en «individuación del alma de España», y, lo que es más irremediable, en prototipo y símbolo de su feminidad eterna: dignidad hispana de mujer prefigurada por otro arquetipo anterior, Carmen ${ }^{5}$. Contrastará la Dama con otras búsquedas del ideal femenino en la segunda mitad del siglo XIX ${ }^{6}$. La ambigüedad formal del busto y el énfasis de sus adornos propiciaron el misterio. Se buscaba un nuevo ideal de belleza, agotada la sensualidad de las Venus griegas. La Dama, además, fundamentó las raíces nacionales prerromanas en una época de profunda crisis de identidad colectiva, tras la pérdida de Cuba, la última colonia ame-

${ }^{3}$ Relación entre imagen ibérica y su recepción social en Olmos, R. et alii, La sociedad ibérica a través de la imagen, Barcelona-Madrid, 1992, 12-13 y 38 ss.

${ }^{4}$ Sobre la recepción del arte ibérico a finales del siglo XIX, cf. Hansen, A.; Hansen, S., «Iberische Plastik und die Rezeption durch die Moderne», Das Altertum, vol. 40, 1995 203-220.

5 Hübner, E., «Die Buste von Illici», Jahrbuch des Archaeologischen Instituts, XIII, 1898; Paris, P., «Buste spagnol de style greco-asiatique trouvé à Elche», Monuments et Mémoires Piot, t. IV, 1898, 137-168; Pijoán, J., «Iberian Sculpture», Burlington Magazine, 1912, 65-74; Havelock Ellis, H., The Soul of Spain, 1908, traducción en castellano, El alma de España, Barcelona, 1928, 120.

${ }^{6}$ Cf. Dijstra, Bram, Idols of Perversity: Fantasies of the Feminine Evil, Nueva York, 1980; Kasson, Joy M., Marble Queens and Captives. Women in Nineteenth-Century American Sculpture, New Haven, Londres, 1990. ricana (1898) y dentro de la creciente irrelevancia de España en el concierto político y artístico europeo. Adquirida de inmediato por el Museo del Louvre, exiliada durante casi medio siglo en Francia, el franquismo de los primeros años 40 la recuperaría gloriosamente para ahondar, ahora desde ideologías totalitarias, en la vieja identidad de una España que, más aislada internacionalmente que nunca, pretendía reencontrarse y bastarse a sí misma durante la penosa autarquía. Es época de manipulaciones de símbolos de la antigüedad en Europa $^{7}$. Pero hoy, desde fuera de España, sigue manteniéndose anacrónicamente este mito: el recensionista anónimo de la Gazette des Beaux-Arts presagia una reacción de los arqueólogos e historiadores españoles: «nul doute que c'est le début d'une controverse» ${ }^{8}$. Para muchos — como para el prologuista del libro de Moffitt, Juan Antonio Ramírez, catedrático de arte contemporáneo en Madrid- demostrar la falsedad de la Dama vendría a cumplir el viejo deseo freudiano de «matar al padre», al desbaratarse uno de los símbolos más queridos por el dictador ${ }^{9}$. Es fácil, entonces, entender la pasión de los argumentos del deconstructor y provocador Moffitt, quien, como el Guillermo de Baskerville (léase Guillermo de Ockham) del Nombre de la Rosa, asume gustoso la identidad de un Sherlock Holmes que se aventura en la jungla de la arqueología ibérica. El argumento podría muy bien haber justificado una novela de detectives. El influjo de este género es claro en el propio discurso del autor y en el subtítulo mismo de la obra (cf. p. XX). Ciertamente, en el pasado la Dama ha dado pie a algún hermoso relato ${ }^{10}$. Pero Moffitt pretende algo más que una mera ficción. Su libro, aunque de lectura fluida, ni convence científicamente ni se sitúa en esas otras evocaciones fantásticas que han tomado como excusa la Dama ". Es un intento fallido.

Trataremos de contrastar los postulados de Moffitt con otros argumentos. De otra manera, podría decirse que la investigación, encerrada en sí misma,

\footnotetext{
${ }^{7}$ Himmelmann, N., Utopische Vergangenheit. Archäologie und moderne Kultur, Berlín, 1976.

${ }^{8}$ Gazette des Beaux-Arts, Sept. 1995, 10

9 Ramírez, J. A., «Foreword. The situation of the Dama de Elche in Post-Franco Spain», en Moffitt, J. F., Art Forgery. The Case of the Lady of Elche, The University Press of Florida, 1995, xv-xxix.

${ }^{10}$ Pereda, C., La Dama de Elche, Instituto de las Españas en Estados Unidos, Nueva York, 1931; Gómez Moreno, M. La novela de España, Granada, 1974, 149.

11 Berlitz, Ch., El misterio de la Atlántida, 1976, 173. Una asociación extraña - no fantástica- en Ginzburg, C., Historia Nocturna, Barcelona, 1991, 114, nos abre a la capacidad de fascinación que suscita en nuestros días la extrañeza de la Dama. Agradecemos la noticia de este libro a M. Fernández.
} 


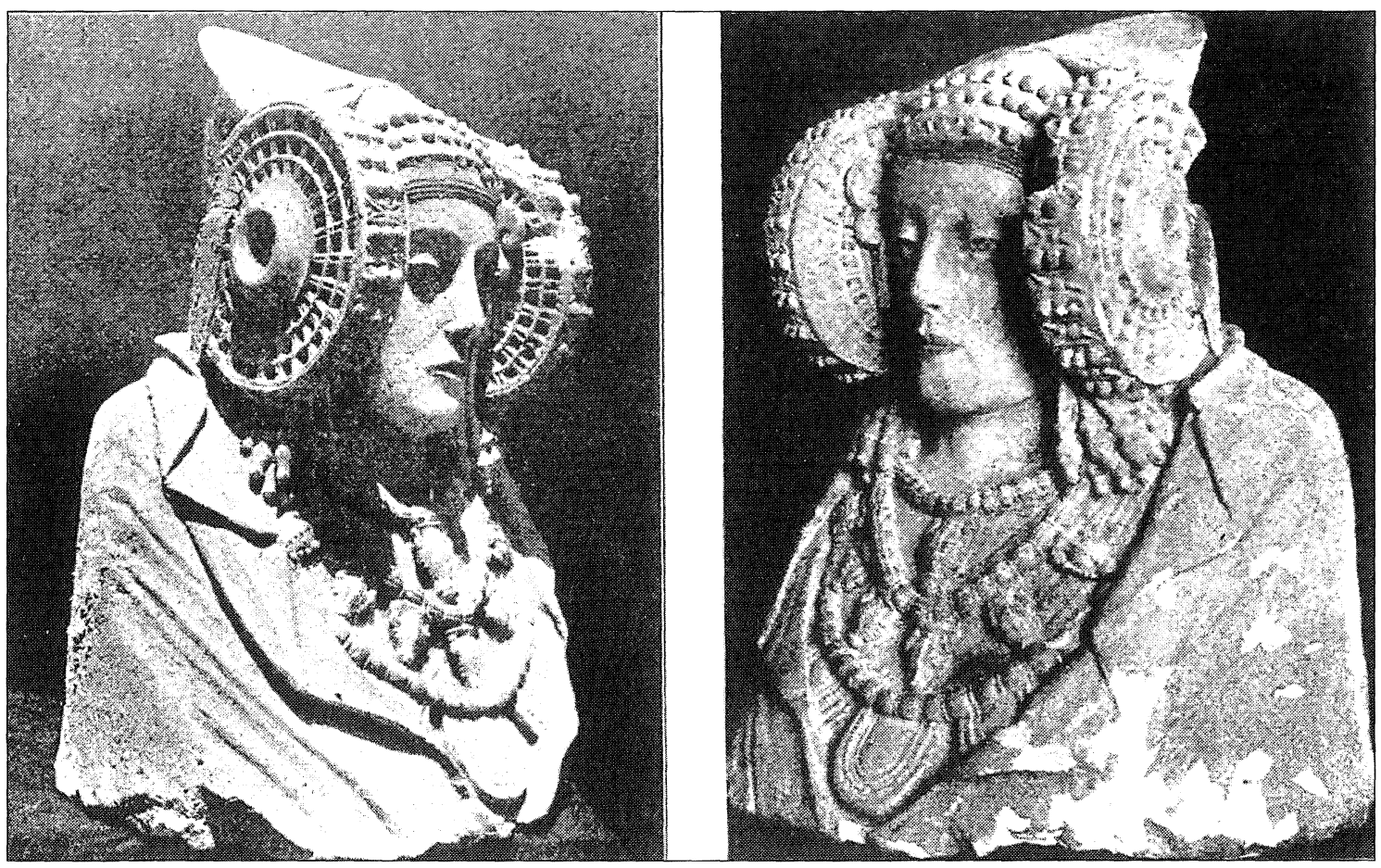

Figs. 1 y 2.-La Dama de Elche, fotografiada por Pedro Ibarra en agosto de 1897, según la publicación de Emil Hübner, JdI, 1898.

se arropa en el consenso que sustenta el poder académico para reaccionar visceralmente contra el intruso que no pertenece a su tribu (véase rec. en $\mathrm{Ga}$ zette des Beaux-Arts, Sept. 1995, 10).

Es preciso analizar simultáneamente método y contenido. El libro se estructura en dos partes: la primera recrea el contexto de la arqueología ibérica en que se situaría la Dáma. La segunda trata de integrar la escultura en el ambiente cultural y artístico de finales del XIX, el modernismo, y en el amplio y heterogéneo contexto de las falsificaciones arqueológicas de todo ese siglo en España. Cierra el libro un capítulo dedicado al influjo del arte ibérico en la plástica contemporánea: Brancusi y Picasso.

Moffitt parte de la intuición, inmediatamente convertida en seguridad, de que la Dama de Elche es una falsificación. No se atrevieron otros, dice (pp. 3 ss.), a explicitar esta sospecha atisbada con anterioridad. Él la lleva hasta las últimas consecuencias. Sin embargo, ya Ricardo Baroja en 1930 propuso argumentos parecidos ${ }^{12}$. El autor del libro se apoya con frecuencia en argumentos de autoridad. Parte, por ejemplo, del conjunto de singularidades sobre la Dama que en 1974 había señalado

12 Caro Baroja, P., «Imagen y derrotero de Ricardo Baroja», Museo de Bellas Artes de Bilbao, 1987, 155. Agradecemos la información a A. Martínez Novillo.
Gérard Nicolini, seis hilos de Ariadna que ahora llevarán brillantemente a Moffitt a desenredar la madeja de este caso ${ }^{13}$. Pero aquí sus argumentos no dejan de ser meras explicitaciones sobre las opiniones de aquellos que, desde su propio conocimiento, vieron en la singularidad de la Dama un enigma. Su capítulo segundo, «The Distinctive characteristics of the Lady of Elche», es fundamentalmente una lectura comentada de las descripciones anteriores de la Dama. La opinión de otros sustituye a una auténtica autopsia de la pieza por Moffitt. Nuestro autor juega continuamente con la imprecisión de una investigación insegura a la hora de clasificar esta pieza en la tipología y en el tiempo ibéricos - hoy se sitúa, aún conjeturalmente, en la segunda mitad del siglo v o primera del IV a. C. ${ }^{14}$. Moffitt convierte la inseguridad de otros en pruebas que fuerza luego con su martillo de Procrustes para adaptarlas al rígido lecho de su pensamiento. Raramente examina

${ }^{13}$ Nicolini, G., «La dame d'Elche: Question d'authenticité», Bulletin de la Société Nationale des Antiquaires de France, April 1974, 60-72

14 Blanco, A., Catálogo de la escultura. Museo del Prado, Madrid, 1957, 130 y ss; id., «Die klassischen Würzeln der Iberischen Kunst», MM, 1, 1960, 101-121; Cunliffe, B., «Core-Periphery Relationships: Iberia and the Mediterranean", en Bild, P. et alii (eds.), Centre and Periphery in Hellenistic World, Aarhus, 1993, 53-85. 
con objetividad los indicios e interpretaciones dentro de su contexto propio, exigencia previa de todo historiador. Así, los rasgos singulares de la Dama, como su carácter de busto, inusual en la escultura prerromana en piedra, su excepcional estado de conservación, la exageración de su carácter indígena, el hieratismo y los grandes rodetes que enmarcan el rostro, etc., son para Moffitt motivo de falsedad. Pero hoy los consideramos simplemente eso, rasgos singulares propios de este arte. La misma Dama de Baza (Granada) no deja de ser un unicum $^{15}$. Sus paralelos con pequeñas terracotas — diosas sentadas en tronos con apéndices alados- nos introducen en el lenguaje mediterráneo. Este juego entre diversos soportes y escalas es frecuente en el arte ibérico. Son igualmente singulares el monumento turriforme de Pozo Moro (Albacete), con escenas únicas, irrepetibles, enigmáticas - y no por ello falsas - como el extrañísimo cocimiento del caldero y el banquete ${ }^{16}$; o el conjunto monumental de las esculturas de Porcuna (Jaén) con una insólita gripomaquia en piedra en pleno siglo V a. C. ${ }^{17}$; o el cipo, inusualmente decorado en su cuatro caras, de Jumilla (Murcia) ${ }^{18}$. El listado de singularidades sería muy amplio. El paradigma ibérico es abierto, inconcluso y novedoso como nos enseñan los recientes descubrimientos escultóricos del Pajarillo (Huelma, Jaén) (1994), o el torso de varón de Baza (Granada) hallado en octubre de 1995 (posiblemente también un busto, como la dama de Elche, con orificio en su espalda) ${ }^{19}$. La misma Alcudia de Elche, donde en el siglo pasado se halló la Dama, ha venido ofreciendo en este siglo un importante número de fragmentos escultóricos, también en gran medida singulares y de excepcional calidad ${ }^{20}$. Esta faceta creativa de lo ibérico, revisable y mudable, no la tiene en cuenta Moffitt. Y cuando se encuentra con la posibilidad de un paralelo, pone énfasis sólo en los rasgos que le interesan y que no rompan su planteamiento. En

\footnotetext{
15 Presedo, F., «La necrópolis de Baza», Excavaciones Ar queológicas de España, 119, 1982

16 Almagro Gorbea, M., «Pozo Moro. Un monumento funerario ibérico orientalizante», $M M, 24,1983,177-293$

17 Negueruela, I., Los monumentos escultóricos ibéricos del Cerrillo Blanco de Porcuna (Jaén), Madrid, 1990; Blázquez, J. M.; González Navarrete, J., «The Phokaian Sculpture of Obulco in Southern Spain», American Journal of Archaeology, 89, 1985, 61-69.

18 Blázquez, J. M., «Iberian Art with Greek Influence: The funerary Monument of Jumilla (Murcia, Spain)», American Journal of Archaeology, 92, 1988, 503-508; Muñoz Amilibia, A.M., "Cipo funerario ibérico decorado con esculturas», XVI Congreso Nacional de Arqueología (Murcia, 1982), 1983, 741-750.

19 Cf. El País, 31-10-1995.

${ }^{20}$ Blanco, A., cit. (n. 14); Ramos, R., «La ciudad romana
} de Illici», Alicante, 1975. nuestra opinión, la Dama de Cabezo Lucero, Alicante (Moffitt, o.c., p. 68, figs. 19-20), hallada en excavaciones recientes y en estado fragmentario, contiene, a pesar de su restauración excesiva, elementos inequívocos y originales en sus adornos singulares (como el tocado de la cabeza, collares, etc.) que la relacionan estrechamente con la Dama de Elche ${ }^{21}$.

Nuestro autor desconoce el paradigma ibérico aunque hable repetidamente de un «Iberian canon of stylistic expectations», según una definición de estilo de E. H. Gombrich (pp. 44 y 48). Moffitt se aferra a un canon imaginario que le van dictando los «anacronismos» y las desviaciones anómalas de la Dama (pp. 93 ss.). Dedica un extenso capítulo, excesivamente simplista, a la escultura ibérica. Caracteriza los ejemplos de la zona contestana, del Sureste español, como «schematic in treatment, summary in depiction, often crude in execution» (p. 44): un tópico generalizador. No tiene en cuenta síntesis y valoraciones actuales como las de Teresa Chapa, que han profundizado en la rica espacialidad, tipología y situación cronológica de estos documentos ${ }^{22}$. Tal vez, por eso, afirme que «the remains of anthropomorfic figurations are much more common than the works of a strictly zoomorphic character» (p. 28). Desconoce a fondo los exvotos en bronce ${ }^{23}$ cuando tan tajantemente sostiene «(...) when the subject matter of an Iberian artwork involves the depiction of a human figure, then the person is inevitably clothed» (p. 28). Su clasificación del espacio ibérico (cap. iii) en tres regiones es ahistórico e ingenuo ${ }^{24}$. Su discurso sobre Ampurias (pp. 35 ss.), obsoleto, resulta perfectamente inútil, al tiempo que peregrino. Trata así de definir unas áreas en las que situar las esculturas. Pero los talleres pueden trabajar por encargos aristocráticos y las obras superar este marco espacial en el que las encierra férreamente Moffitt. Un mismo taller ha podido esculpir la cabeza femenina, posiblemente procedente de Alicante, depositada en el Museo de Barcelona y la cabeza de Úbeda La Vieja (Jaén $)^{25}$. La confusión histórica entre lo púnico y lo

${ }^{21}$ Llobregat, E.; Jodin, A., «La Dama del Cabezo Lucero (Guardamar del Segura, Alicante)», Saguntum, 23, 1990, 109-122.

${ }^{22}$ Chapa, T., La escultura ibérica zoomorfa, Madrid, 1985; eadem, Influjos griegos en la escultura zoomorfa, Iberia Graeca. Serie Arqueológica, 2, Madrid, 1986.

${ }^{23}$ Las tipologías del desnudo masculino y femenino, cf. Prados, L., Exvotos ibéricos de bronce del Museo Arqueológico Nacional, Madrid, 1992.

${ }^{24}$ Para el territorio ibérico cf. Ruiz, A.; Molinos, M., Los Iberos. Análisis arqueológico de un proceso histórico, Ed. Crítica, Barcelona, 1991.

${ }^{25}$ Cf. Blech, M.; Ruano, E., «Zwei Iberische Skulpturen aus Ubeda La Vieja-Jaén», MM 33, 1992, 70-101, que parece desconocer el autor. 
fenicio es constante. Así, la dama de Galera, producción oriental del s. VII, es para Moffitt púnica (p. 35); denomina a Gades colonia cartaginesa como Carthago Nova, etc. (p. 42). Su tratamiento de tópicos sobre la debatida cuestión de colonias foceas como Mainake o Hemeroscopeion (p. 41) es más propia de los años 20 (Rhys Carpenter, 1925) ${ }^{26}$, cuando se intentaban localizar, que de los 90, mientras que su concepción de las funciones «helenizadoras» de la colonización griega es anacrónica y mecánica, e insostenible, al menos ya desde los años $70{ }^{27}$. El esquema histórico se basa en lecturas acríticas de otros autores -incorpora aquello que le interesa- y deviene rígido y anticuado: explica exclusivamente el pasado ibérico con los tópicos del «rise and fall» de una civilización y parece entenderlo de forma pasiva, como mera secuencia de conquistas militares o influjos mecánicos de pueblos mediterráneos que se proyectan e imprimen de forma inmediata en el arte ibérico. Desconoce la dialéctica y la originalidad indígena, ignora la complejidad del proceso. La influencia púnica no existe; la griega se prolonga y cesa, como de repente, en 150 a. C. tras la conquista romana: el arte ibérico ya no será griego sino de cuño romano, se extingue «almost instantly» (p. 42): un simplismo estremecedor. A lo largo del libro toma afirmaciones de aquí y allá, sin el menor sentido crítico. La Dama de Baza, a la que dedica un capítulo sin desperdicio, sería herencia etrusca, el influjo de cuya thalassocracia nuestro autor defiende llegando a proponer afinidades lingüísticas entre el ibérico y el etrusco: un perfecto disparate (p. 274, n. 10). Desconoce los términos del debate actual sobre la presencia etrusca en la Península ${ }^{28}$. En el mejor de los casos, son opiniones de hace un cuarto de siglo, recogidas de otros y mal digeridas. Su atrevimiento se extiende, pues, al campo lingüístico: si vincular el vasco moderno con las lenguas caucásicas como el georgiano es retroceder varias décadas, afirmar que la actual lengua vasca es «post-Iberian» (p. 274, n. 10) parece, sencillamente, volver al siglo XIX, a las teorías, hoy superadas, que se nutrieron de Humboldt ${ }^{29}$. Moffitt

\footnotetext{
${ }^{26}$ The Greeks in Spain, Pennsylvania, 1925.

27 Para el tema cf., ex gratia, Domínguez Monedero, A. «New perspectives on the Greek presence in the Iberian Peninsula", en Fossey, J. M. (ed.), Proceedings of the Ist International Congress on the Hellenic Diaspora, vol. 1, Amsterdam, 1991, 109-161.

${ }^{28}$ Cf. Remesal, J.; Musso, O. (eds.), La presencia de material etrusco en la Península Ibérica, Barcelona, 1991.

${ }_{29}$ El profesor Javier de Hoz de la Universidad Complutense de Madrid amablemente nos comenta en carta, desde su punto de vista de lingüista, las págs. 274-275 del libro de Moffitt: «Es difícil reunir tantos disparates en poco más de
}

(p. 275) lucubra inútilmente sobre la concurrencia del nombre antiguo de la Iberia póntica y la occidental ${ }^{30}$.

Semejante totum revolutum revierte en su argumentación sobre la falsedad de la Dama. Todo le conviene. Toma las opiniones de muchos autores -que tuvieron lugar y justificación en el determinado momento histórico en que se dijeron pero que, evidentemente, hoy en su mayoría ya no sirvenpara tejer un discurso prefigurado y tendencioso. Por ejemplo, los viejos tópicos de la helenización de la escultura ibérica, de formulaciones mudables ${ }^{31}$, o el concepto de retrato en el mundo antiguo cuya problemática y diversidad desconoce o trivializa ${ }^{32}$. Efectivamente, la Dama no puede ser entendida como retrato en nuestro sentido moderno sino como eikón o representación tipológica e idealizada de un personaje: una mortal, una diosa o una mujer en el tránsito hacia el allende, ese singular ámbito de la representación que embellece y adorna al aristócrata, a los meliores, como vemos también en los nobles guerreros de Porcuna ${ }^{33}$. El rostro, el busto, concentran la identidad del representado. Actitud psicológica y adornos, inseparablemente, integran la imagen.

Tampoco parece haber entendido Moffitt el mundo sutil de los gestos antiguos (pp. 45 y 95-96). Considera una anomalía la caracterización «psicológica» de la Dama: su singularidad es extraña a esa norma ibérica que el autor previamente establece. Sin embargo, lejos de ser moderna esta expresión,

una página. No sé quiénes son los lingüistas que creen en el «West-Mediterranean». Ibérico y etrusco no tienen nada en común; «aglutinante» es tan útil para relacionar lenguas como «no blanco» para relacionar etnias; no es seguro que exista una familia caucásica y nadie ha presentado nunca una prueba de parentesco entre el vasco y ninguno de los tres grupos lingüísticos del Cáucaso. La bibliografía citada es una aberración, o en calidad (el Penguin Atlas of Ancient History) o en fecha (Menéndez Pidal, En torno a la lengua vasca). Moffitt, que cree como Hübner que había una lengua paleohispánica, se permite recomendarnos la metodología de M. Ventris, que sirve para descifrar escrituras, aunque el autor americano cree que sirvió para determinar la lengua del Lineal B, cuando la escritura ibérica está descifrada hace tres cuartos de siglo».

30 Para un análisis argumentado véase Domínguez Monedero, A., "Los términos "Iberia" e "Iberos" en las fuentes grecolatinas: estudio acerca de su origen y ámbito de aplicación», Lucentum II, 1983, 203-224; K. H. Schmidt, "The Two Ancient Iberias from the Linguistic Point of View», Studia Paleohispánica, Vitoria, 1987, 105-121.

31 Langlotz, E., Die kulturelle und künstlerische Hellenisierung der Küsten des Mittelmeers durch die Stadt Phokaia, Colonia, 1966; Chapa, T., cit. (n. 22, 1986), 311 ss.

${ }_{32} \mathrm{Cf}$. Fittschen, K. (ed.) Griechische Porträts, Darmstadt, 1988; Scheibler, I.; Zanker, P.; Vierneisel, K., Sokrates in der griechischen Bildniskunst, Munich, 1989; etc.

${ }^{33}$ Blázquez, J. M.; González, J., cit. (n. 17), fig. 11. 
podemos leer la ligera inclinación de los ojos como insinuación de aidós o pudicitia, un rasgo psicológico antiguo que también recoge la mirada de la mujer ante el varón en la pequeña estela de la Albufereta, Alicante ${ }^{34}$. Coindice bien con el pudor femenino de quien se muestra: un gesto contenido, regulado socialmente. Pues cabe leer la Dama como mostración sacral, iniciática, tal vez epifánica, de un alto personaje femenino.

El autor podría haber analizado mejor la Dama, en sí misma y dentro de la escultura ibérica. Pues basa uno de sus argumentos en la apreciación subjetiva del connoisseur, en su olfato de lo falso. No es lícito negar la validez de este criterio de familiaridad a verdaderos expertos, como fue el caso de G.M.A. Richter, quien lo utilizó sabia y prudentemente para el arte de la antigüedad ${ }^{35}$. Gisela Richter, sí, estaba autorizada a servirse de este criterio, tras cientos de horas dedicadas a la escultura clásica. No creemos que sea éste el caso de John F. Moffitt. Su descripción somera olvida por completo la pequeña fíbula anular que ciñe la fina túnica interior de la Dama: un claro rasgo de adecuación entre la fíbula y la calidad del vestido ceñido al cuerpo. Conocemos fíbulas de este tipo, tan diminutas, en la arqueología ibérica: por ejemplo, en Pozo Moro ${ }^{36}$. Las llevan, en idéntico lugar bajo el cuello, los innumerables bustos en terracota o pebeteros, hallados a lo largo de toda la costa ibérica desde el siglo IV a. C. ${ }^{37}$. Difícilmente un falsificador del s. XIX captaría detalles como éste o como el complejo tratamiento de las diferentes texturas de los vestidos de la Dama.

John F. Moffitt también pasa por alto una característica común a la representación humana del ibérico antiguo: las leves disimetrías de adornos y pliegues (cf., similarmente, Damas de Baza y del Llano de la Consolación; Moffitt, o.c., figs. 15-17), que indican la relación entre el vestido y el cuerpo que late debajo, un asomo de conciencia de vida propia en la imagen. No entiende el juego de las proporciones ibéricas, que resaltan expresivamente aquello

\footnotetext{
${ }^{34}$ Olmos, R. et alii, cit. (n. 3), 129.

${ }^{35}$ Richter, G.M.A., The Sculpture and Sculptors of the Greeks 4th, New Haven-Londres, 1970, 141: ella enfatiza «in my opinion».

${ }^{36}$ Blanco, A., cit. (n. 14, 1957), 132, dice: «La fíbula anular de tipo hispánico, que aparece en esta estatua en el borde de la túnica, se encuentra ya en los yacimientos ibéricos desde el comienzo del siglo V (ajuar de una tumba de Galera).. ajuares de dos tumbas de Ampurias con cerámica ática de la primera mitad del siglo v.»

37 Pena, M. J., «Los thymiateria en forma de cabeza femenina en el noreste de la Península Ibérica», Grecs et Ibères au IV s. av. J.C. Revue des Etudes Anciennes 89, 3-4, 1987, 349-358.
}

que pretenden subrayar, y las considera un énfasis moderno. Cae en el viejo error de querer leer, negativamente, los adornos de la Dama desde los textos acudiendo, una vez más, al manido pasaje de Estrabón (Geographia, III,4,17) que recogió de Artemidoro, sobre los singulares tympánia con que se adornaban las mujeres ibéricas (pp. 179-180). Claro está: el alto tocado de la Dama de Elche no corresponde estrictamente con la descripción de Artemidoro. Ciertamente, hubiera sido una casualidad. Parecía ya agotada en nuestro campo esa vieja tradición de la arqueología filológica en estas equiparaciones mecánicas. Hemos de analizar los relatos y descripciones de los autores antiguos dialécticamente y desde sus propios códigos, intereses y universo referencial. Constataremos así la selección de una realidad infinitamente más amplia, por un lado; y la independencia entre la ékphrasis y la cultura material, por otro.

Las características del hallazgo, confusas, son para John Moffitt otro indicio, otra prueba. Y el móvil, la necesidad de dinero rápido del dueño del terreno de la Alcudia, quien tendería una trampa al viajero y experto francés Pierre Paris (Moffitt, o.c., cap. XIII). Este hallazgo fue casual como han sido, por desgracia, la mayoría de los descubrimientos ibéricos y se envuelve de esa pasión y emoción extraordinarias que han suscitado tantas veces otras estatuas singulares. Tal vez no menos oscuras, por ejemplo, fueron las circunstancias que rodearon el encuentro y adquisición de la Venus de Milo en el s. XIX ${ }^{38}$. No por ello es falsa. El azar acaece tanto en arqueología como en la misma vida: coincidió el descubrimiento de la Dama con la llegada anunciada del arqueólogo francés. Pero ¿no es mayor azar que en este mismo yacimiento hayan aparecido esculturas notables a lo largo de todo el siglo xx? Más valiera haber analizado aquel momento de expectación arqueológica que justificaba la visita de Pierre Paris a España y el colonialismo europeo anunciado por E. Hübner ${ }^{39}$, donde se esperaba un nuevo Schliemann en España.

Moffitt sigue con el caso. Junto a las circunstancias del hallazgo fingido y su móvil económico, le llega la hora al falsificador. Hay, efectivamente, un ambiente de falsificaciones en el siglo XIX, que afecta de manera singular a lo ibérico. Conocidas son las falsificaciones de las esculturas del Cerro de los Santos a lo largo de la década de 1870, que acompañaron, esperpénticamente, el primer descu-

\footnotetext{
${ }^{38}$ Pasquier, A., La Vénus de Milo et les Aphrodites du Louvre, París, 1985, 21 ss.

${ }^{39}$ Hübner, E., La arqueología de España, Barcelona, 1888, 222.
} 


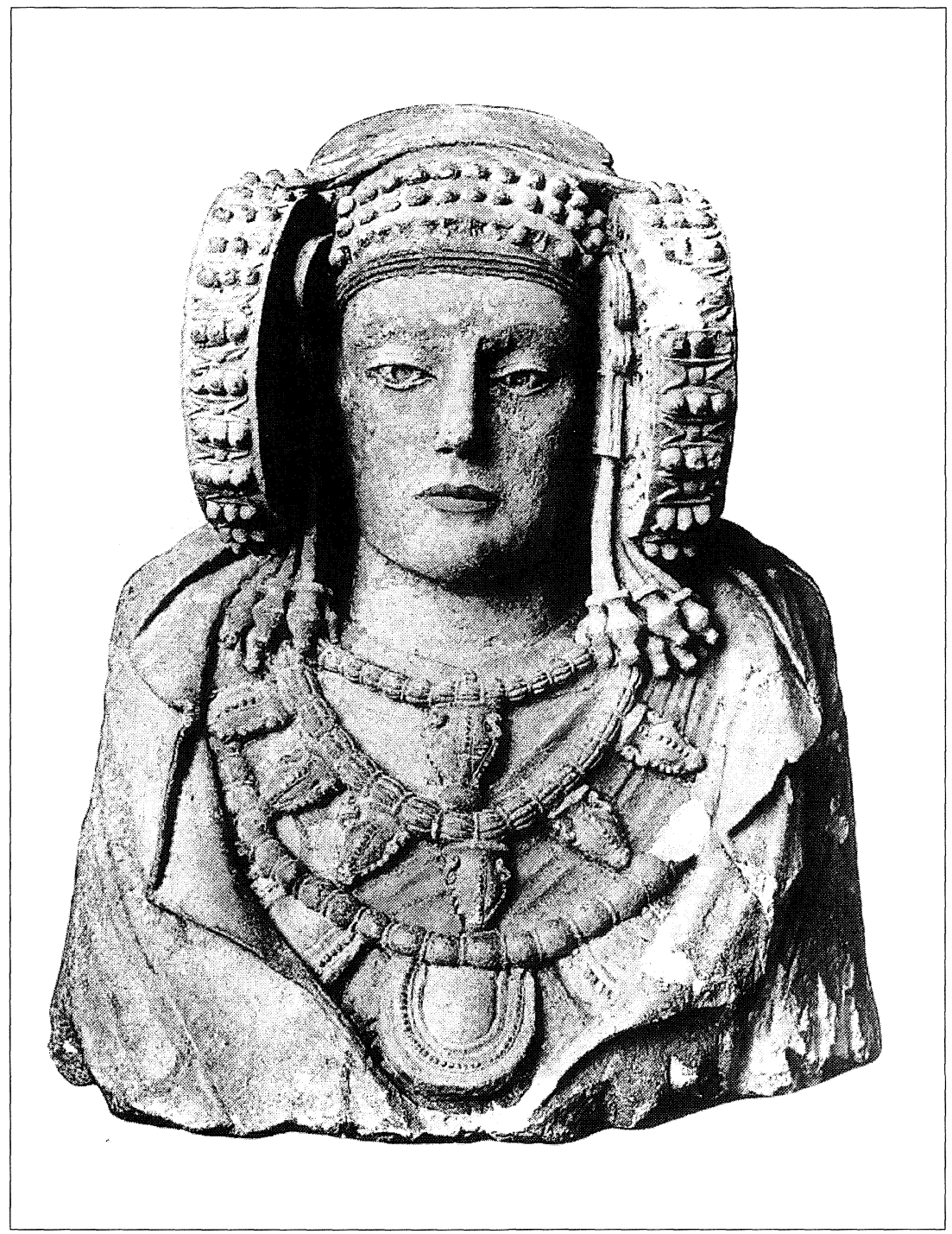

Fig. 3.-La Dama de Elche, en la publicación de Pierre Paris, Essai sur l'art..., París, 1903, lám. XII.

brimiento de lo ibérico. Es un fenómeno complejo a estudiar en otro lugar ${ }^{40}$. John Moffitt cree encontrar la horma de su zapato en un falsificador valenciano, Pallás i Puig, que imitó marfiles góticos por aquellos años ${ }^{41}$. La existencia de falsificadores coetáneos no prueba nada. Los hubo por doquier. Moffitt, de nuevo, unifica y simplifica en su análisis las enormes diferencias de falsificadores e imi-

40 Olmos, R., «Una aproximación historiográfica a las imágenes ibéricas», Al otro lado del espejo, Madrid, 1996, 41 ss.

${ }^{41}$ Gómez Moreno, M., «Los marfiles cordobeses y sus derivaciones», Archivo Español de Arte y Arqueología, 9, 1927, 233-243. Agradecemos a I. Izquierdo las «pesquisas» sobre Pallás i Puig, en Valencia. tadores de diverso tipo. Le sigue faltando esa sensibilidad para captar la diferencia de cada fenómeno histórico. La obra de Pallás i Puig, el presunto falsificador, se inserta en otro horizonte de recreaciones, con modelos más inmediatos y con referentes conocidos; es un imitador de estética neomedieval y trabaja sobre un soporte tan diferente de la piedra como es el marfil: no tiene nada que ver. La Dama de Elche posee unos rasgos o estilemas propios que, de ser falsa, implicarían una invención complejísima de elementos materiales y estilísticos del mundo ibérico, lo que resulta imposible en el estado de conocimientos de finales del siglo XIX. No basta suponer la pequeña y tosca figura femenina, encontrada anteriormente en el Cerro de los 
Santos que, según Moffitt (fig. 51), sería el modelo conocido por el falsificador a través de una lámina. Tienen ambas de común adornos y rodetes enmarcando el rostro. Por cierto, la relación formal ya había sido sugerida por Pierre Paris, quien vio en el ejemplar del Cerro de los Santos una reminiscencia degenerada de la Dama ${ }^{42}$. No creemos que sea lícito ir más allá de una mera analogía formal. Por otra parte, Pallás i Puig no practicó el trabajo en piedra ni fatigó el campo de la antigüedad. ¿Adivinó acaso que esta precisa y frágil policromía ibérica - rojo y azul - se documentaría más tarde en otras esculturas halladas en La Alcudia? ${ }^{43}$. Inimaginable.

Contento con su éxito y sus ganancias, Pallás i Puig, añade Moffitt, falsificaría al año siguiente un torso de guerrero ibérico, que aliviaría la soledad femenina de la Dama (Moffitt, o.c., pp. 214 ss., fig. 56). También le encuentra con facilidad otro modelo: un torso de varón de la necrópolis del Llano de la Consolación (Albacete) poco antes dibujado por el francés A. Engel (Moffitt o.c., pp. 214 ss., figs. 57-58). Pallás i Puig, falsificador clarividente, le añadiría una falcata. Ciertamente, imposible: los detalles precisos del arma ibérica, el modo singular indígena de llevar horizontalmente la vaina junto al costado, sujeta por anillas, estaban entonces aún lejos de conocerse. Todos estos detalles tan específicos relativos al armamento ibérico han sido, poco a poco, iluminados por toda una paciente investigación reciente ${ }^{44}$. También la leve inclinación del torso que ataca, y las proporciones de los poderosos muslos del varón son, sin duda, rasgos propios de la escultura ibérica ${ }^{45}$. No existen motivos de sospecha.
El estilo presuntuoso del libro, el mal uso de los argumentos, el atrevimiento del autor al tratar de forma indiscriminada y descontextualizada los tópicos de la cultura ibérica son un modelo a evitar en la investigación futura y deben invitar hoy a reflexión. A esto se añade la responsabilidad de la crítica fácil en la citada recensión del $A J A$, sancionadora del disparate, que ha motivado nuestra respuesta. Es peligroso introducir en el circuito científico libros oportunistas que no son lo que pretenden. Por otra parte, ha de reconocerse también una dosis de culpa desde nuestra propia situación: hemos descuidado los iberistas la difusión de la cultura ibérica al proyectar poco su investigación fuera de España. No hemos sido buenos comunicadores más allá del reducido círculo de especialistas.

En todo caso, volvamos al argumento inicial de la Dama. Quede abierta la discusión en torno a esta obra, que nosotros seguimos considerando auténtica. Puede debatirse, si se quiere, su autenticidad en este juego incierto de la ciencia. Pero hágase con rigor, sin dogmatismos huecos e introduciendo argumentos dialécticos en el paradigma abierto y siempre enriquecedor de lo ibérico. Propongamos debates, análisis, modelos nuevos que, lejos de agotar nuestras inquisiciones sobre la Dama, permitan acercarnos a las matizaciones continuas y propuestas mudables de la investigación. Una Mesa Redonda e interdisciplinar sobre La Dama de Elche: lecturas desde la diversidad, celebrada en Madrid el pasado mes de noviembre (1996), podrá abrir nuevas perspectivas para la discusión. Será preciso que todos abandonemos la retórica con que hayamos podido envolver a esta escultura: es muy poco aún lo que sabemos de ella.

\footnotetext{
42 Paris, P., cit. (n. 5) 149: «On ne doit donc pas juger sans prudence le style du fragment; mais, d'autre part, on ne peut nier qu'il ne reproduise avec une frappante exactitude le vêtement, la parure, l'attitude du buste d'Elche... Dès lors on serait tenté de supposer que la figure actuellement au Louvre est justement celle dont la statuette du Cerro est la copie réduite». El tópico lo recogerán también otros autores en su preocupación por el estudio de los adornos singulares, véase especialmente Jacobsthal, P., «Zum Kopfschmuck des Frauenkopfes von Elche», Athenische Mitteilungen, 57 1932, 67-73.

${ }^{43}$ Ramos Folqués, A., «La escultura ibérica y las excavaciones de Albertini en la Alcudia de Elche», Archivo Españo de Arqueología XXV, 1952, 119-123.

${ }_{44}$ Quesada, F., Arma y símbolo: la falcata ibérica, Alicante, 1992.

${ }^{45} \mathrm{Cf}$. similares guerreros de Porcuna en Negueruela, I., cit. (n. 17)
} 